\title{
Rational Speculators, Contrarians and Excess Volatility
}

\author{
Matthijs Lof \\ University of Helsinki and HECER
}

Discussion Paper No. 358

November 2012

ISSN 1795-0562

HECER - Helsinki Center of Economic Research, P.O. Box 17 (Arkadiankatu 7), FI-00014 University of Helsinki, FINLAND, Tel +358-9-191-28780, Fax +358-9-191-28781, E-mail info-hecer@helsinki.fi, Internet www.hecer.fi 


\title{
Rational Speculators, Contrarians and Excess Volatility*
}

\begin{abstract}
The VAR approach for testing present value models is applied to a nonlinear asset pricing model with three types of agents, using historical US stock prices and dividends. Besides rational long-term investors, that value assets according to expected dividends, the model includes rational and contrarian speculators. Agents choose their regime based on evolutionary considerations. Supplementing the standard present value model with speculative agents dramatically improves the model's ability to replicate the observed market dynamics. In particular the existence of contrarians can explain some of the most volatile episodes including the 1990s bubble, suggesting this was not a rational bubble.
\end{abstract}

JEL Classification: C58, D84, G11

Keywords: asset pricing, heterogeneous agents, VAR approach

Matthijs Lof

Department of Political and Economic Studies

University of Helsinki

P.O. Box 17

FI-00014 University of Helsinki

FINLAND

e-mail: matthijs.lof@helsinki.fi

* I thank Markku Lanne and participants at the HECER time series econometrics seminar and the Aalto finance brown bag seminar for constructive comments. The Academy of Finland, the Finnish Foundation for Advancement of Securities Markets and the OPPohjola Research Foundation are gratefully acknowledged for financial support. 


\section{Introduction}

Prices of financial assets are typically more volatile than real economic activity. As a result, it is often impossible to associate asset price fluctuations with news regarding dividends underlying the asset. This excess volatility of asset prices with respect to dividends has been documented in many studies, such as Shiller (1981), Campbell and Shiller (1987), West (1988), or the survey by Gilles and LeRoy (1991). The behavioral finance literature has proposed various models to accommodate this excess volatility as well as other market anomalies (See e.g. the surveys by Hirshleifer, 2001, Barberis and Thaler, 2003, and Shiller, 2003). In such models, price movements can occur due to investor sentiment rather than fundamental news. Agents may make investment decisions based on expected price movements in the short run rather than expected dividends in the long run and often form non-rational expectations based on limited information sets and underparameterized models (See e.g. De Long et al., 1990a,b, Barberis et al., 1998, or Hong and Stein, 1999).

I consider a simple asset pricing model with three types of agents: Rational long-term investors, rational speculators and contrarians. These agents are allowed to have heterogeneous investment horizons and may form heterogeneous expectations regarding shortterm price movements. Nevertheless, all three types hold identical information sets and have their expectation formation mechanisms anchored in the same vector autoregressive (VAR) representation of prices and dividends. The model can therefore be evaluated empirically using the VAR approach for testing present value models, pioneered by Campbell and Shiller (1987, 1988), for which I use a dataset containing annual observations on the S\&P500 index and underlying dividends for the period 1871-2011 ${ }^{1}$. Even if there is no disagreement at all among the agents regarding expected dividends, the model is able to generate prices far more volatile than the standard present value model. Statistical tests indicate that the model is preferred to alternative representative agent models.

The first two agent types both act in accordance with the standard present value model.

\footnotetext{
${ }^{1}$ Source: http://www.econ.yale.edu/ shiller
} 
The only characteristic separating these agents is their investment horizon. The first type makes long-term investments and therefore values assets according to the cash flows (dividends) that the asset is expected to generate. I refer to agents of this type as rational long-term investors, while the term fundamentalism is also used in the literature to describe this behavior.

The second type is only interested in one-period returns, so that the main determinant of the asset's current value is the expected selling price in the next period. This speculative behavior is similar to that of the trend followers or the momentum traders considered in the literature, for example by Brock and Hommes (1998), or Hong and Stein (1999). However, while trend followers and momentum traders in general form expectations based on a simple univariate model and a limited information set, typically by extrapolating recent returns, the short-term investors considered in this paper form expectations by using the exact same model and information set as the rational long-term investors. I therefore refer to these agents as rational speculators.

I refer to the first two types of agents as rational, even if they are, strictly speaking, boundedly rational. Their expectation formation mechanism is based on a VAR model. These expectations would be fully rational if the VAR is the true data generating process. Although I show that the VAR provides an appropriate characterization of the data, it remains only an approximation, which does not take all aspects of the data generating process, such as the existence and strategies of other agents, explicitly into account.

The third type of agent also follows a short-term strategy. Regarding expected price changes, however, this type takes the exact opposite, or contrarian, stance from the rational speculators. These agents are therefore referred to as contrarian speculators, or contrarians. When the rational speculators expect an $x \%$ increase in the price, the contrarians expect an $x \%$ decrease and vice versa.

Several studies provide empirical evidence showing that agents do indeed sometimes embark on such contrarian strategies, (e.g. Kaniel et al., 2008, or Grinblatt and Keloharju, 2000), which is further supported by experimental evidence by Bloomfield et al. (2009). 
In addition, Park and Sabourian (2011) provide a theoretical justification of contrarian behavior, while Lakonishok et al. (1994), Jegadeesh and Titman (1995), and Dechow and Sloan (1997) discuss the profitability of such strategies. This paper does not provide a theory or intuition for contrarian behavior. Instead, I motivate the existence of contrarians empirically, by showing that observed market dynamics can be replicated rather well when a certain fraction of market participants is forming contrarian expectations. While the existence of rational speculators can explain much of the volatility observed on financial markets, the contrarians turn out to be an essential element of the model in order to approximate observed prices also in terms of correlation.

Contrarian beliefs are in particular helpful in explaining the high valuations that the stock market reached at the end of the 1990s, mainly driven by technology stocks. Whether this episode constituted a bubble has been the subject of debate among many authors, including Ofek and Richardson (2003), Pástor and Veronesi (2006), Bradley et al. (2008), O'Hara (2008) and Phillips et al. (2011). The results in this paper indicate that dividend expectations are not the dominant factor in the observed price increases during the 1990s. In this sense, it could be justified to classify this event as a bubble. Nevertheless, it was not a rational bubble as defined by Blanchard and Watson (1982), since the results show that rational speculators would have driven the market in the opposite direction. Instead, the observed dynamics of the 1990s can be closely approximated by the contrarian valuation model, suggesting that nonrational beliefs inflated this bubble.

To capture the observed regime switching behavior of financial markets (documented by e.g. Ang and Bekaert, 2002, or Guidolin and Timmermann, 2008), I allow the agents to switch between strategies. Agents are assumed to observe the recent performance of each strategy and choose their own strategy accordingly, following the evolutionary selection scheme introduced by Brock and Hommes $(1997,1998)$. This scheme has been applied in many theoretical and empirical studies of heterogeneous agent models in finance, including Boswijk et al. (2007), Branch and Evans (2010) and Lof (2012b). Similar concepts, in which agents apply learning principles to update expectations are considered by Timmer- 
man (1994), Hong et al. (2007), and Branch and Evans (2011), among others. Hommes et al. (2005) and Bloomfield and Hales (2002) provide experimental evidence in favor of such principles being applied in the formation of expectations. Alternatively, the fractions of different types of agents may be held constant (Szafarz, 2012), or vary according to an exogenous process, such as the business cycle (Lof, 2012a).

The VAR approach for testing present value models is recently applied by Cornea et al. (2012) to a heterogeneous agent model of the New Keynesian Philips curve, in which price-setters are allowed to switch between forward looking and naive inflation expectations. Only the expectations of the forward looking price-setters are evaluated using the VAR approach, since the naive expectations are not model-based. In this paper, on the other hand, I let all three types of agents form expectations based on the same VAR framework.

This paper proceeds as follows. The next section outlines the present value model, the concept of rational bubbles and the log-linear approximation by Campbell and Shiller (1988). In Section 3, the VAR approach is reviewed and applied to three representative agent models, in which the representative agent is either a rational long-term investor, a rational speculator or a contrarian. In Section 4, these models are merged into one regime switching model. The section further includes estimation results and specification tests. In Section 5, the model is generalized to allow for time-varying discount factors. Section 6 concludes.

\section{The present value model and rational bubbles}

According to the standard present value model, the price of an asset should equal the discounted present value of the cash flows (dividends) that an asset is expected to generate:

$$
P_{t}=\sum_{i=1}^{\infty} \delta^{i} E_{t}\left[D_{t+i}\right]
$$


in which which $P_{t}$ refers to the asset price and $D_{t}$ to its underlying dividend. The discount factor $\delta$ is for simplicity assumed to be constant. In Section 5, I examine the validity of this assumption by considering several time-varying discount factors. Assuming rationality and market efficiency requires that the conditional expectation operator $E_{t}[\cdot]$ is the optimal prediction conditional on all available information. Because in equation (1), the value is entirely determined by expected dividends, or fundamentals, this expression is sometimes referred to as the fundamental value which would be equal to the observed market price if all agents are rational fundamentalists (e.g. Szafarz, 2012).

Agents are not necessarily planning to hold the asset for a long period and may be more interested in the short-term trading profits rather than long-term dividend yields. If agents are planning to hold the asset for a short time only, say one period, the value of the asset should equal the discounted sum of the expected dividend paid out in the next period and the expected price at which the asset can be sold subsequently:

$$
P_{t}=\delta E_{t}\left[P_{t+1}+D_{t+1}\right]
$$

The long-term model (1) is the solution to the short-term model (2) under the following transversality condition:

$$
\lim _{i \rightarrow \infty} \delta^{i} P_{t+i}=0
$$

Hence, under this transversality condition the investment horizon of the agents should not have an impact on the price. However, equation (2) has a more general solution which does allow for a discrepancy between equations (1) and (2):

$$
P_{t}=\sum_{i=1}^{\infty} \delta^{i} E_{t}\left[D_{t+i}\right]+C_{t}
$$

in which $C_{t} \equiv \delta^{-1} C_{t-1}$, or equivalently, $C_{t} \equiv \delta^{-t} M_{t}$, in which $M_{t}$ may be any martingale process (i.e. $E_{t}\left[M_{t+1}\right]=M_{t}$ ). Because $C_{t}$ constitutes a discrepancy between the fundamental value and the observed price, it may be referred to as a bubble. However, since the 
bubble exists due to a violation of the transversality condition rather than the a violation of rationality, Blanchard and Watson (1982) name it a rational bubble. The finding that rational dividend expectations are not sufficiently volatile to explain observed price volatility can be regarded as a rejection of the present value model (1) and is often interpreted as evidence in favor of rational bubbles (Gürkaynak, 2008).

Two recent studies present theoretical analyses of asset pricing models in which longterm fundamentalists and short-term speculators co-exist. Szafarz (2012) finds that the existence of multiple investment horizons is a potential source of price volatility. Anufriev and Bottazzi (2012), however, argue that variation in the investment horizon has a significant effect on market dynamics only when agents hold heterogeneous expectations about future prices. In this paper, I follow an empirical approach by applying the VAR-based tests of present value models by Campbell and Shiller $(1987,1988)$ to an asset pricing model with heterogeneity in both investment horizons and expectations. As will become evident in the next section, heterogeneity in investment horizons can explain the high level of volatility observed in stock prices. Nevertheless, heterogeneity in expectations appears to be a crucial element required for generating prices that do not only capture the volatility but also obtain a relatively high correlation with observed stock prices.

Before proceeding to estimation of the VAR it is preferable to apply the log-linear approximation of the present value model derived by Campbell and Shiller (1988). The return on holding an asset for one period $\left(R_{t+1}=\left(P_{t+1}+D_{t+1}\right) / P_{t}\right)$ can be approximated by a linear equation:

$$
r_{t+1}=\rho p_{t+1}-p_{t}+(1-\rho) d_{t+1}+k
$$

in which $p_{t} \equiv \log \left(P_{t}\right), d_{t} \equiv \log \left(D_{t}\right)$ and $r_{t} \equiv \log \left(R_{t}\right)$. The parameter $\rho$ is below, but close to, one: It denotes the mean of the ratio $\frac{P_{t}}{P_{t}+D_{t}}$, which Campbell and Shiller (1988) assume to be approximately constant over time. Following Campbell and Shiller (1988), the constant term $k$ is ignored in much of the analysis below, because explaining price 
movements rather than levels, is the main objective of this study. Engsted et al. (2012) show by simulation that these log-linear returns are a close approximation to true returns even in the presence of rational bubbles.

The assumption of a constant discount factor as in equations (1)-(2) implies that expected returns are constant:

$$
E_{t}\left[R_{t+1}\right]=\frac{E_{t}\left[P_{t+1}+D_{t+1}\right]}{P_{t}}=\delta^{-1}
$$

Taking conditional expectations on both sides of equation (5), substituting constant expected returns $\left(E_{t}\left[r_{t+1}\right] \equiv \bar{r}\right)$ and re-arranging gives:

$$
y_{t}=\rho E_{t}\left[y_{t+1}\right]+E_{t}\left[\triangle d_{t+1}\right]+k-\bar{r},
$$

in which $y_{t} \equiv p_{t}-d_{t}$ denotes the log price-dividend (PD) ratio. Equation (7) can be iterated forward to obtain the long-term interpretation of the present value model, in which the valuation of the asset is determined by expected future dividend growth rates:

$$
y_{t}=\sum_{i=0}^{\infty} \rho^{i} E_{t}\left[\triangle d_{t+1+i}\right]+\frac{k-\bar{r}}{1-\rho} .
$$

This solution requires the assumption of a transversality condition:

$$
\lim _{i \rightarrow \infty} \rho^{i} y_{t+i}=0
$$

which, like condition (3), excludes the possibility of a rational bubble. Equation (8) can be interpreted as the log-linear equivalent of (1).

It is also possible to derive a short-term interpretation of the log-linear present value model, in which the value of an asset is determined by the expected return of holding the asset for one period. Subtracting $\rho y_{t}$ from equation (7) and dividing both sides by $1-\rho$ 
gives:

$$
y_{t}=\frac{\rho}{1-\rho} E_{t}\left[\triangle y_{t+1}\right]+\frac{1}{1-\rho} E_{t}\left[\triangle d_{t+1}\right]+\frac{k-\bar{r}}{1-\rho},
$$

or, since $\triangle y_{t}=\triangle p_{t}-\triangle d_{t}$ :

$$
y_{t}=\frac{\rho}{1-\rho} E_{t}\left[\triangle p_{t+1}\right]+E_{t}\left[\triangle d_{t+1}\right]+\frac{k-\bar{r}}{1-\rho} .
$$

In this model the PD ratio is entirely determined by one-period expectations of the change in the price and dividend. Since the parameter $\rho$ is below but close to one, the ratio $\frac{\rho}{1-\rho}$ is a rather large number, implying that the expected price change is the dominant factor in the valuation of the asset. Dividend expectations therefore only play a minor role in this short-term valuation model, akin to the models by Hong et al. (2007) and Branch and Evans (2010), in which agents have the option to omit dividends partly or entirely from their expectation formation mechanism.

Unlike the long-term model (8), the short-term model (11) does not require the transversality condition (9) and therefore allows for the existence of a rational bubble. In the next section, I evaluate both models (8) and (11) using the VAR approach by Campbell and Shiller $(1987,1988)$.

\section{The VAR approach}

Campbell and Shiller (1988) propose to test the log-linear present value model (8) based on an estimated $\operatorname{VAR}(q)$ for the $\operatorname{PD}$ ratio and the dividend growth rate:

$$
v_{t} \equiv\left[\begin{array}{c}
y_{t} \\
\triangle d_{t}
\end{array}\right]=\sum_{i=0}^{q} A_{i} v_{t-1}+u_{t}
$$

Both the PD ratio and the dividend growth rate are demeaned so that intercept terms are not required and the parameters $k$ and $\bar{r}$ in (8) can be disregarded. I estimate a VAR(2) for annual observations of the PD ratio and the dividend growth rate over the period 
1872-2011. The lag length of $q=2$, is selected using the Akaike Information Criterion (AIC). This lag order is consistent with the results of Campbell and Shiller (1988). Table 1 depicts the AIC for different lag lengths, as well as diagnostic tests for the selected VAR(2). The second-order VAR seems to describe the data well as there is no sign of autocorrelation or heteroscedasticity in the residuals. Moreover, the results of a Chow forecast test at several potential break points indicate that parameter constancy can not be rejected.

TABLE 1: VAR specification and diagnostics

\begin{tabular}{lcccccc}
\hline lags & 1 & 2 & 3 & 4 & 5 & 6 \\
AIC & -7.980 & -7.986 & -7.967 & -7.953 & -7.889 & -7.889 \\
\hline Autocorrelation & 17.63 & $(0.612)$ & & & & \\
Heteroscedasticity & 51.62 & $(0.231)$ & & & & \\
\hline Breakpoint & 1890 & 1910 & 1930 & 1950 & 1970 & 1990 \\
Chow FC & 0.578 & 0.403 & 0.345 & 0.998 & 0.976 & 0.624 \\
\hline
\end{tabular}

Notes: VAR(q) model (12), with annual data for 1872-2011. Top: Lag selection based on Akaike information criterion. Middle: LM-type test statistics (p-values in parentheses) for Autocorrelation (5 lags) and Multivariate ARCH (5 lags) in residuals of VAR(2). Bottom: P-values for Chow forecast test for parameter constancy. All three diagnostic tests are executed with JMulti (Lütkepohl and Krätzig, 2004)

In order to proceed with testing the present value model, it is convenient to consider the VAR(2) model in its companion form:

$$
\left[\begin{array}{c}
v_{t} \\
v_{t-1}
\end{array}\right]=\left[\begin{array}{ll}
A_{1} & A_{2} \\
I_{2} & O_{2,2}
\end{array}\right]\left[\begin{array}{c}
v_{t-1} \\
v_{t-2}
\end{array}\right]+\left[\begin{array}{c}
u_{t} \\
O_{2,1}
\end{array}\right],
$$

or:

$$
z_{t}=B z_{t-1}+\varepsilon_{t}
$$

in which $z_{t} \equiv\left(v_{t}, v_{t-1}\right)^{\prime}$. If this VAR provides an accurate description of the data, which the diagnostics in Table 1 indeed suggest, the matrix of estimated parameters $B$ can be used to replicate the conditional expectations in equation (8), and to compute a time- 
series of theoretical PD ratios:

$$
\begin{aligned}
y_{t}^{r l}=\sum_{i=0}^{\infty} \rho^{i} E_{t}\left[\triangle d_{t+1+i}\right] & =\sum_{i=0}^{\infty} \rho^{i}\left(e_{2}^{\prime} B^{i} z_{t}\right) \\
& =e_{2}^{\prime} B(I-\rho B)^{-1} z_{t},
\end{aligned}
$$

in which $e_{i}$ is a vector of zeros in which the $i$ th element is replaced by one. A full derivation is provided Campbell and Shiller (1988). The superscript $r l$ to the theoretical PD ratio indicates rational and long-term. The generated theoretical PD ratio can be interpreted as an estimate of how the PD ratio would behave if all agents are rational long-term investors, that value assets according to rational expectations of future dividends.

For now, the parameter $\rho$ is calibrated at a fixed value, as in Campbell and Shiller (1988). I set $\rho=0.958$ which is the sample average of the ratio $\frac{P_{t}}{P_{t}+D_{t}}$. At the end of this section, I discuss the sensitivity of the results with respect to this calibration.

Figure 1 shows the theoretical PD ratio $\left(y_{t}^{r l}\right)$, as well as the realized PD ratio $\left(y_{t}\right)$. The figure looks similar to the charts in Campbell and Shiller (1987). The theoretical PD ratio is quite strongly correlated with the realized PD ratio $\left(\operatorname{corr}\left(y_{t}^{r l}, y_{t}\right)=0.799\right)$, but the volatility of the theoretical PD ratio falls far behind of observed volatility. This is illustrated by the volatility ratio $\left(\sigma\left(y_{t}^{r l}\right) / \sigma\left(y_{t}\right)=0.135\right)$, which expresses the standard deviation of the theoretical PD ratio as a fraction of the standard deviation of the realized PD ratio. The long-term present value model (15) therefore seems able to explain the direction of the stock market, but lacks explanatory power regarding the observed volatility of the stock market. Already in the 1980s, Campbell and Shiller, among others, interpreted this excess volatility as a rejection of present value models. In fact, as Figure 1 shows, the discrepancy between the theoretical and observed PD ratio has only increased further since then, with an unprecedented rise in the PD ratio during the 1990s, which the present value model fails to capture.

The VAR approach can also be applied to the short-term model (11), which is the correct model if all agents are rational speculators. These agents are speculators, as they are mainly interested in short-term trading profits rather than in the dividends the asset 


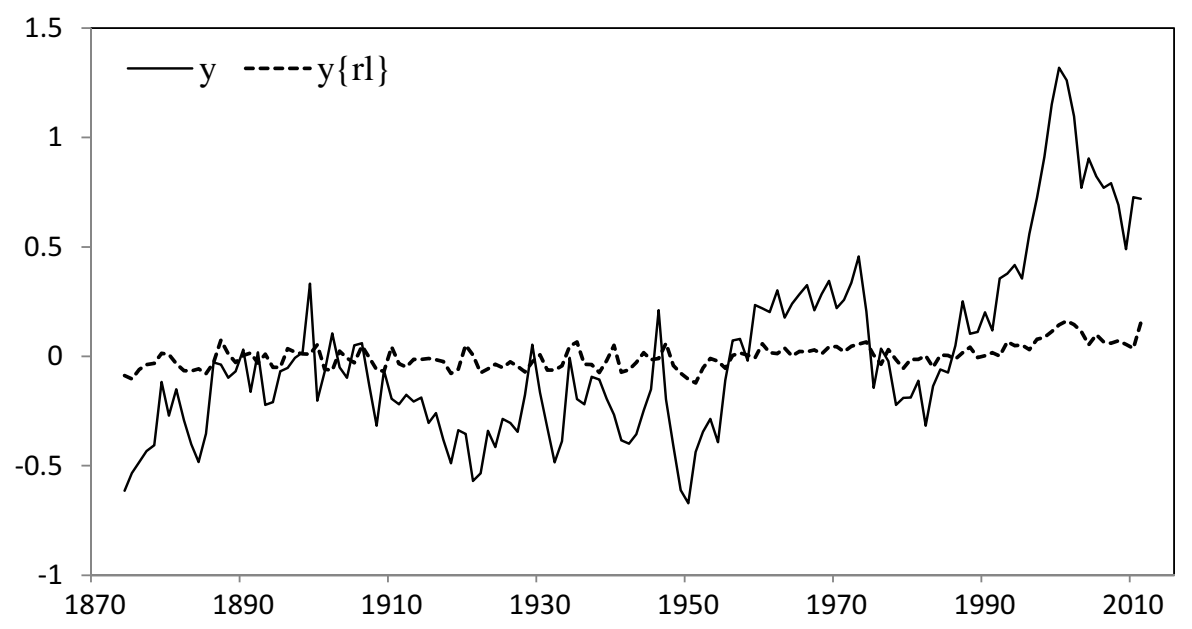

Figure 1: Observed PD ratio $\left(y_{t}\right)$ and theoretical PD ratio $\left(y_{t}^{r l}\right)$, from long-term model (15), with $\rho=0.958 . \operatorname{corr}\left(y_{t}, y_{t}^{r l}\right)=0.799 . \frac{\sigma\left(y_{t}^{r l}\right)}{\sigma\left(y_{t}\right)}=0.135$.

generates in the long run. They can be considered (boundedly) rational, however, as they form expectations using the same information set and VAR model as the long-term investors considered above. The conditional expectations of these rational speculators $(r s)$ can therefore be replicated based on the estimated VAR, similar as above:

$$
y_{t}^{r s}=\frac{\rho}{1-\rho} E_{t}\left[\triangle p_{t+1}\right]+E_{t}\left[\triangle d_{t+1}\right]
$$

in which:

$$
E_{t}\left[\triangle d_{t+1}\right]=e_{2}^{\prime} B z_{t}
$$

and:

$$
\begin{aligned}
E_{t}\left[\triangle p_{t+1}\right] & =E_{t}\left[\triangle y_{t+1}\right]+E_{t}\left[\triangle d_{t+1}\right] \\
& =E_{t}\left[y_{t+1}\right]-y_{t}+E_{t}\left[\triangle d_{t+1}\right] \\
& =e_{1}^{\prime}(B-I) z_{t}+e_{2}^{\prime} B z_{t}
\end{aligned}
$$

In addition, I consider the valuation model according to a second type of speculator: Contrarian speculators $(c s)$ or simply: Contrarians. These agents agree with the rational agents on expected dividends, but form alternative expectations on expected changes in prices:

$$
y_{t}^{c s}=\frac{\rho}{1-\rho} \tilde{E}_{t}^{c s}\left[\triangle p_{t+1}\right]+E_{t}\left[\triangle d_{t+1}\right]
$$




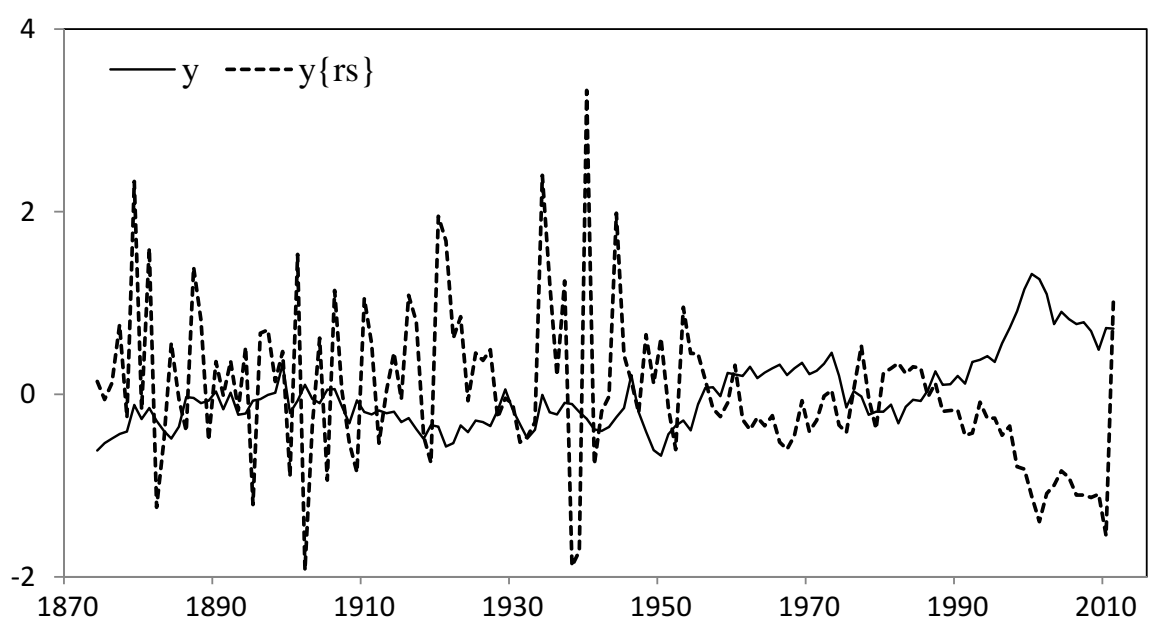

Figure 2: Observed PD ratio $\left(y_{t}\right)$ and theoretical PD ratio $\left(y_{t}^{r s}\right)$, from rational speculative model (16), with $\rho=0.958$. $\operatorname{corr}\left(y_{t}, y_{t}^{r s}\right)=-0.403 . \frac{\sigma\left(y_{t}^{r s}\right)}{\sigma\left(y_{t}\right)}=2.065$.

In fact, regarding the expected price change, contrarians take the exact opposite stance from the rational speculators:

$$
\tilde{E}_{t}^{c s}\left[\triangle p_{t+1}\right]=-E_{t}\left[\triangle p_{t+1}\right]
$$

Figure 2 shows $y_{t}^{r s}$ and $y_{t}$. The model with rational speculative expectations (16) appears able to generate large price fluctuations, with the volatility of the theoretical PD ratio even overshooting observed volatility $\left(\sigma\left(y_{t}^{r s}\right) / \sigma\left(y_{t}\right)=2.065\right)$. Nevertheless, the correlation with the observed PD ratios is very weak, even negative $\left(\operatorname{corr}\left(y_{t}^{r s}, y_{t}\right)=-0.403\right)$. From Figure 2, it can be seen that during several episodes, most notably the 1990s, the theoretical PD ratio moves in the opposite direction from the observed PD ratio. The rational speculative model (16) therefore fails to explain the 1990s bull market any better than the long-term model (15) does.

Figure 3 shows the empirical need for a model with contrarian expectations. The theoretical PD ratio $y_{t}^{c s}$, which is generated by model (19), nearly matches $y_{t}^{r s}$ in terms of volatility: $\left(\sigma\left(y_{t}^{c s}\right) / \sigma\left(y_{t}\right)=1.977\right)$. Unlike the rational speculative model, however, the contrarian model generates a PD ratio that is positively correlated with the observed PD ratio $\left(\operatorname{corr}\left(y_{t}^{c s}, y_{t}\right)=0.447\right)$. Although this correlation remains quite low compared to 


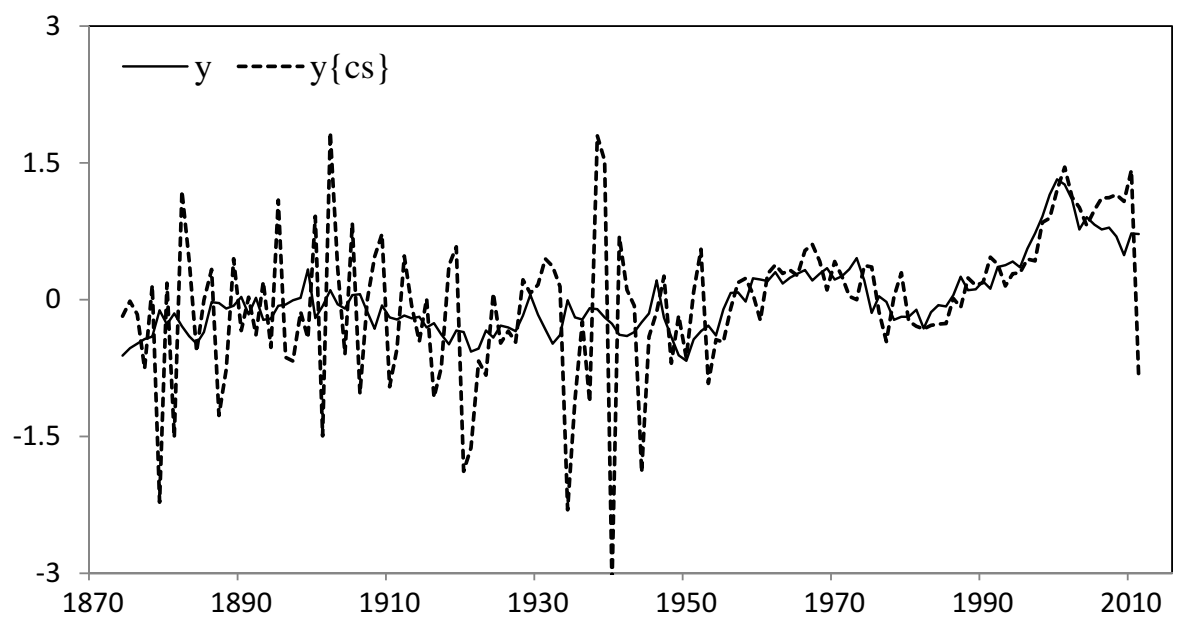

Figure 3: Observed PD ratio $\left(y_{t}\right)$ and theoretical PD ratio $\left(y_{t}^{c s}\right)$, from contrarian model (19), with $\rho=0.958 . \operatorname{corr}\left(y_{t}, y_{t}^{c s}\right)=0.447 . \frac{\sigma\left(y_{t}^{c s}\right)}{\sigma\left(y_{t}\right)}=1.977$.

the long-term model (15), it is evident from Figure 3 that in recent decades the contrarian model traces the observed PD ratio remarkably well.

Based on Figure 1, it can be argued that the bull market in the 1990s was a bubble. It was, however, not a rational bubble, as in that case the rational speculative model (Figure 2) should be able to replicate the bubble. Instead, I find that the model requires nonrational, or contrarian, beliefs in order to explain the 1990s bubble.

It is evident from Figures 1-3 that the performance (or fit) of the three alternative models changes over time, which could indicate misspecification of the VAR, due to the existence of structural breaks or time-varying parameters. The diagnostic tests presented
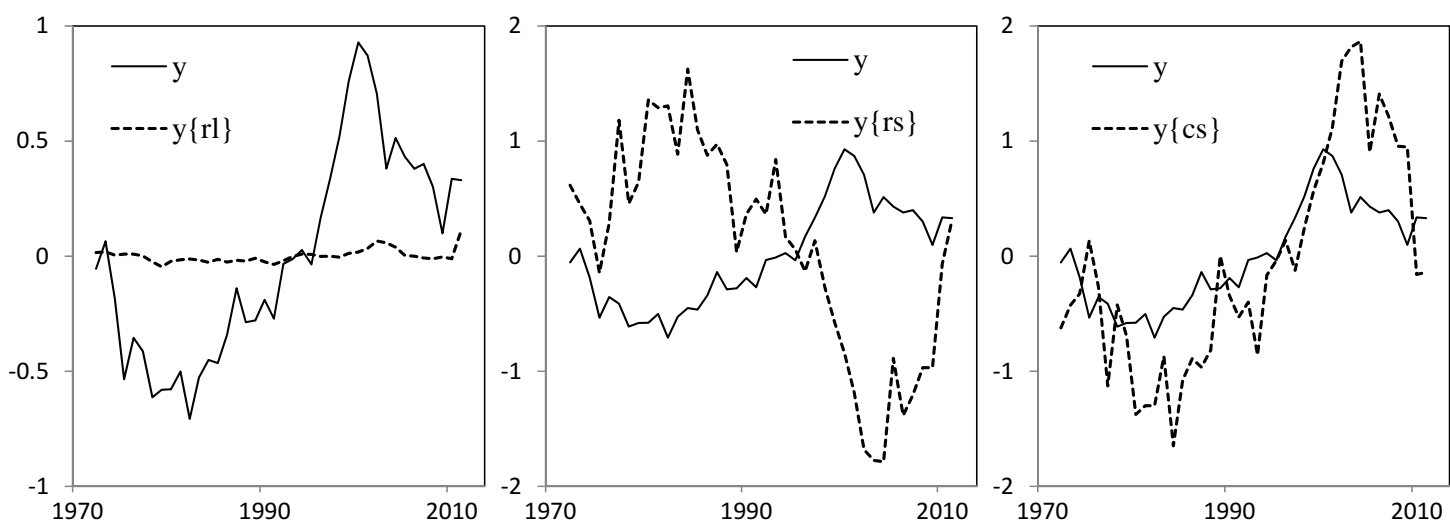

Figure 4: Observed PD ratio $\left(y_{t}\right)$ and theoretical PD ratio $\left(y_{t}^{r l}, y_{t}^{r s}\right.$, and $\left.y_{t}^{c s}\right)$, from models (15), (16), and (19), for 1972-2011. 

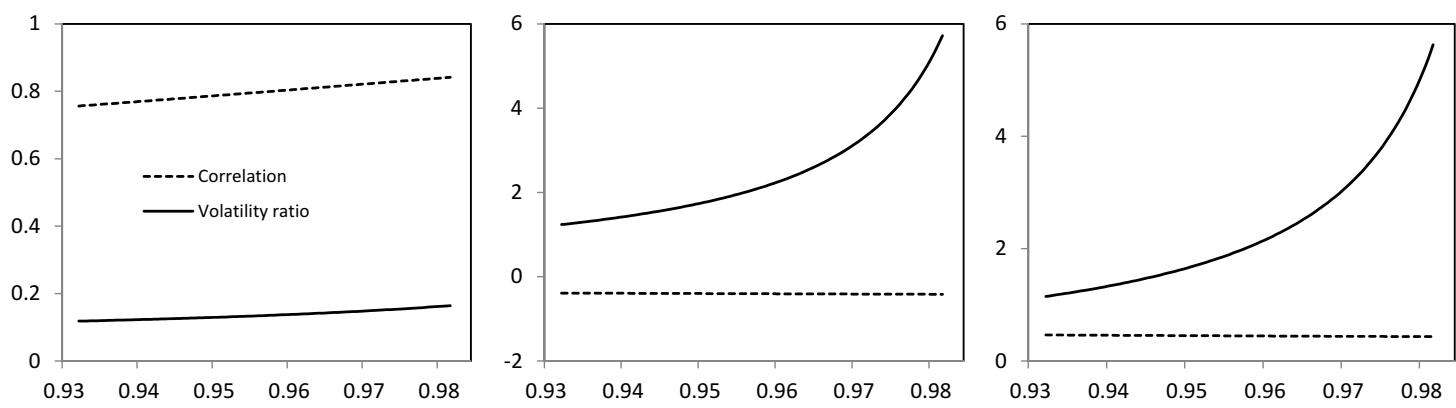

Figure 5: $\operatorname{corr}\left(y_{t}, y_{t}^{j}\right)$ and $\frac{\sigma\left(y_{t}^{j}\right)}{\sigma\left(y_{t}\right)}$ for different values of $\rho$, for $j=r l$ (left), $j=r s$ (middle) and $j=c s$ (right)

in Table 1, however, indicate that the VAR is correctly specified. In addition, I estimate the VAR and generate $y_{t}^{r l}, y_{t}^{r s}$ and $y_{t}^{c s}$ again for the last 40 years in the sample only, which are presented in Figure 4. These plots tell a roughly similar story as Figures 1-3, suggesting that the time-varying performance of the three models is not the result of misspecification of the VAR.

Instead, the time-varying fit of the three models could indicate that the market is subject to regime switching behavior, with agents switching between the long-term strategy based on expected dividends, and more speculative (rational or contrarian) strategies. In the next section, I therefore combine equations (15), (16) and (19) into one regime switching model, in which the asset price is determined by the interaction of rational long-term investors, rational speculators and contrarians.

So far, the parameter $\rho$ is calibrated at the sample average of the ratio $\frac{P_{t}}{P_{t}+D_{t}}$. The obtained results are somewhat sensitive to this calibration. This is illustrated in Figure 5, which shows volatility ratios and the correlation between realized and theoretical PD ratios, for different values of $\rho$, for all three models. For the long-run model, the sensitivity with respect to $\rho$ is rather modest. Campbell and Shiller (1988) make the same observation. For the speculative models, however, small changes in $\rho$ do have a great impact. Calibrating $\rho$ and disregarding its uncertainty seems therefore inappropriate. Instead, I estimate $\rho$ in the remainder of this paper jointly with the other parameters in the model. 


\section{Heterogeneous agents}

The results in the previous section indicate that the long-run present value model (15) can explain the direction of stock market movements, but not its excess volatility. The speculative models (16) and (19) are able to generate sufficient volatility, but their correlation with the observed market falls short of the long-run model. In an attempt to specify a model which is able to capture both correlation and volatility, I consider an economy in which all three agents (long-term rational investors, rational speculators and contrarians) are present:

$$
y_{t}^{h a}=G_{t}^{r l} y_{t}^{r l}+G_{t}^{r s} y_{t}^{r s}+G_{t}^{c s} y_{t}^{c s}
$$

in which the subscript $h a$ denotes heterogeneous agents. The fractions of each type of agent are denoted by $G_{t}^{l r}, G_{t}^{s r}$ and $G_{t}^{s c}$ and are allowed to vary over time. This process of switching between agent types or regimes is modeled based on evolutionary selection following Brock and Hommes (1998), such that the fraction of each type of agents increases if its predictions outperform the other types. The predictions of each type are evaluated by a measure of fitness representing the distance between the theoretical PD ratio and the realized PD ratio in the previous period:

$$
U_{t}^{j}=-\left\|y_{t-1}^{j}-y_{t-1}\right\| \quad j \in\{r l, r s, c s\} .
$$

The fractions of each type are then determined by multinomial logit probabilities:

$$
G_{t}^{j}=\frac{\exp \left(\beta^{j} U_{t}^{j}\right)}{\sum_{k} \exp \left(\beta^{k} U_{t}^{k}\right)} \quad j, k \in\{r l, r s, c s\}
$$

such that the fractions of the three types sum to one. The parameters $\beta$ denote the intensity of choice, which indicate the willingness of agents to switch between strategies. While Brock and Hommes (1998) hold $\beta$ constant across types, I allow for type-specific intensities of choice. This setting accommodates the idea by Hong et al. (2007) that agents 


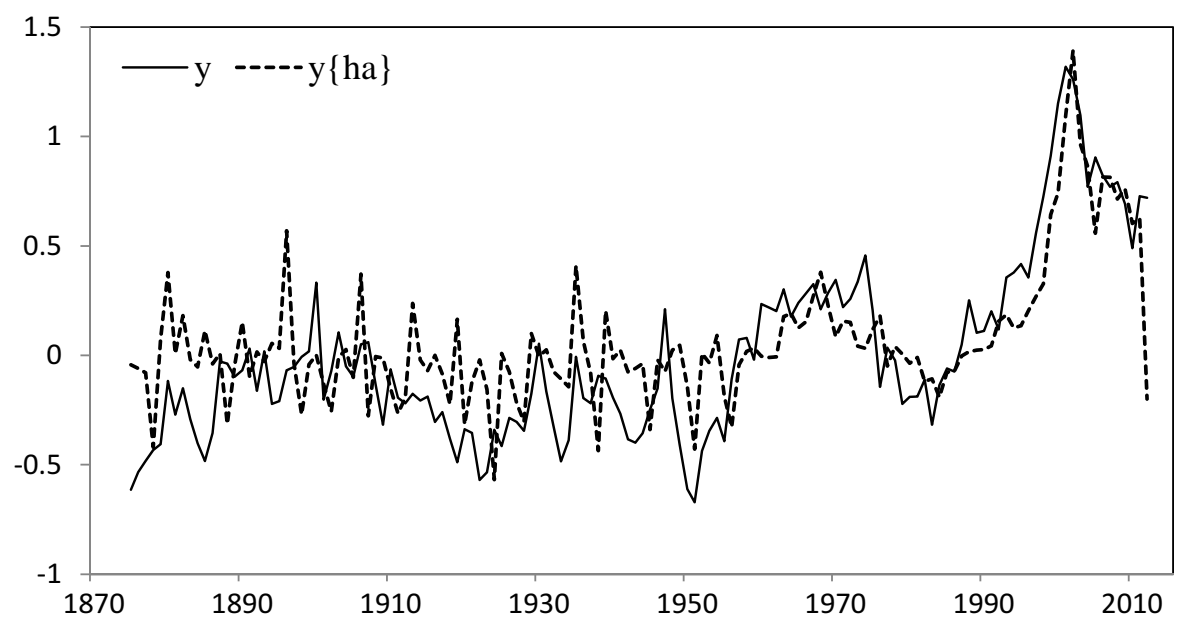

Figure 6: Observed PD ratio $\left(y_{t}\right)$ and theoretical PD ratio $\left(y_{t}^{h a}\right)$, from heterogeneous agent model (21), with $\rho$ and $\beta$ estimated by NLS (See Table 2). $\operatorname{corr}\left(y_{t}, y_{t}^{h a}\right)=0.759$. $\frac{\sigma\left(y_{t}^{h a}\right)}{\sigma\left(y_{t}\right)}=0.752$.

may hold heterogeneous thresholds for switching between strategies.

To obtain estimates of $\beta$ and $\rho$, I estimate the following model by nonlinear least squares (NLS):

$$
y_{t}=y_{t}^{h a}+\varepsilon_{t} .
$$

The top row of Table 2 shows the parameter estimates, while Figure 6 shows a plot of the theoretical PD ratio $y_{t}^{h a}$. The generated PD ratio is highly correlated with the realized PD ratio; $\operatorname{corr}\left(y_{t}^{h a}, y_{t}\right)=0.759$, which is of the same magnitude as the correlation coefficient for the long-term model considered in Section 3. The volatility ratio for the heterogeneous agent model is, however, much larger $\left(\sigma\left(y_{t}^{h a}\right) / \sigma\left(y_{t}\right)=0.752\right)$. Unlike the representative agent models considered in Section 3, the heterogeneous agent model is able to explain both the direction as well as the volatility of the observed PD ratio to a large extent.

The fitted values of model (24), $\widehat{y}_{t}^{h a}$, are used to estimate the following regression by OLS:

$$
y_{t}=\phi \widehat{y}_{t}^{h a}+\varepsilon_{t}
$$

Table 2 reports the estimate and standard error of $\phi$, showing that the null hypothesis that $\phi=1$ can not be rejected.

In order to take into account the uncertainty underlying the estimated parameters in 
TABLE 2: Estimation results

\begin{tabular}{|c|c|c|c|c|c|c|c|c|}
\hline & $\rho$ & $\beta_{1}$ & $\beta_{2}$ & $\beta_{3}$ & $\phi$ & $\sigma\left(y_{t}^{j}\right) / \sigma\left(y_{t}\right)$ & $\operatorname{corr}\left(y_{t}, y_{t}^{j}\right)$ & $R^{2}$ \\
\hline \multirow[t]{2}{*}{$h a$} & 0.966 & 0.799 & 5.175 & 1.125 & 0.962 & 0.752 & 0.759 & 0.548 \\
\hline & $(0.004)$ & $(0.599)$ & $(6.156)$ & $(0.401)$ & $(0.029)$ & & & \\
\hline \multirow[t]{2}{*}{$r l$} & 1.000 & . & . & . & 4.474 & 0.193 & 0.865 & 0.297 \\
\hline & $(0.073)$ & & & & $(0.548)$ & & & \\
\hline \multirow[t]{2}{*}{$r s$} & 0.000 & . & . & . & 3.933 & 0.080 & 0.317 & 0.044 \\
\hline & $(0.000)$ & & & & $(0.497)$ & & & \\
\hline \multirow[t]{2}{*}{$c s$} & 0.000 & . & . & . & 3.933 & 0.080 & 0.317 & 0.044 \\
\hline & $(0.202)$ & & & & $(0.568)$ & & & \\
\hline
\end{tabular}

Notes: NLS estimates and measures of fit for model (21)-(24). ha: Heterogeneous agents and evolutionary dynamics (22)-(23). $r l: G_{t}^{r l}=1, G_{t}^{r s}=G_{t}^{c s}=0 . r s: G_{t}^{r s}=1, G_{t}^{r l}=G_{t}^{c s}=0 . c s: G_{t}^{c s}=1, G_{t}^{r l}=G_{t}^{r s}=0 . \phi$ is estimated by model (25). Annual data for 1872-2011. Standard errors (in in parentheses) are computed using 10.000 bootstrap replications.

the VAR model (12), all standard errors in Table 2 are based on the following bootstrap procedure:

1. Generate simultaneously an artificial series $(T+100$ observations $)$ of dividend growth rates from the VAR model (12) using the parameter estimates $\widehat{B}$, and an artificial series $(T+100$ observations) of PD ratios from the model (21)-(24) using the parameter estimates $\widehat{\beta}$ and $\widehat{\rho}$. The innovations to both series are drawn (with re-sampling) from the fitted residuals $e_{2}^{\prime} \widehat{u}_{t}$ and $\widehat{\varepsilon}_{t}$.

2. Use the last $\mathrm{T}$ observations from both artificial series to estimate models (24) and (25). Store the estimates $\widetilde{\beta}, \widetilde{\rho}$ and $\widetilde{\phi}$.

3. Repeat steps 1 and $2 R$ times. For each parameter, the standard deviation of the $R$ artificial estimates is reported in Table 2 as the parameter's standard error.

For this procedure, I set $T=138$, equal to the sample size in the estimations, while the number of replications $R=10.000$.

Figure 7 shows the estimated fractions of each type of agent over time. Rational long-term investors are always present in the economy, with their fraction of the total population fluctuating for most of the time between roughly $40 \%$ and $100 \%$. After 1950, their fraction stays close to the lower bound of this interval, suggesting that expected dividends have lost relevance as a determinant of asset prices. This is consistent with the 

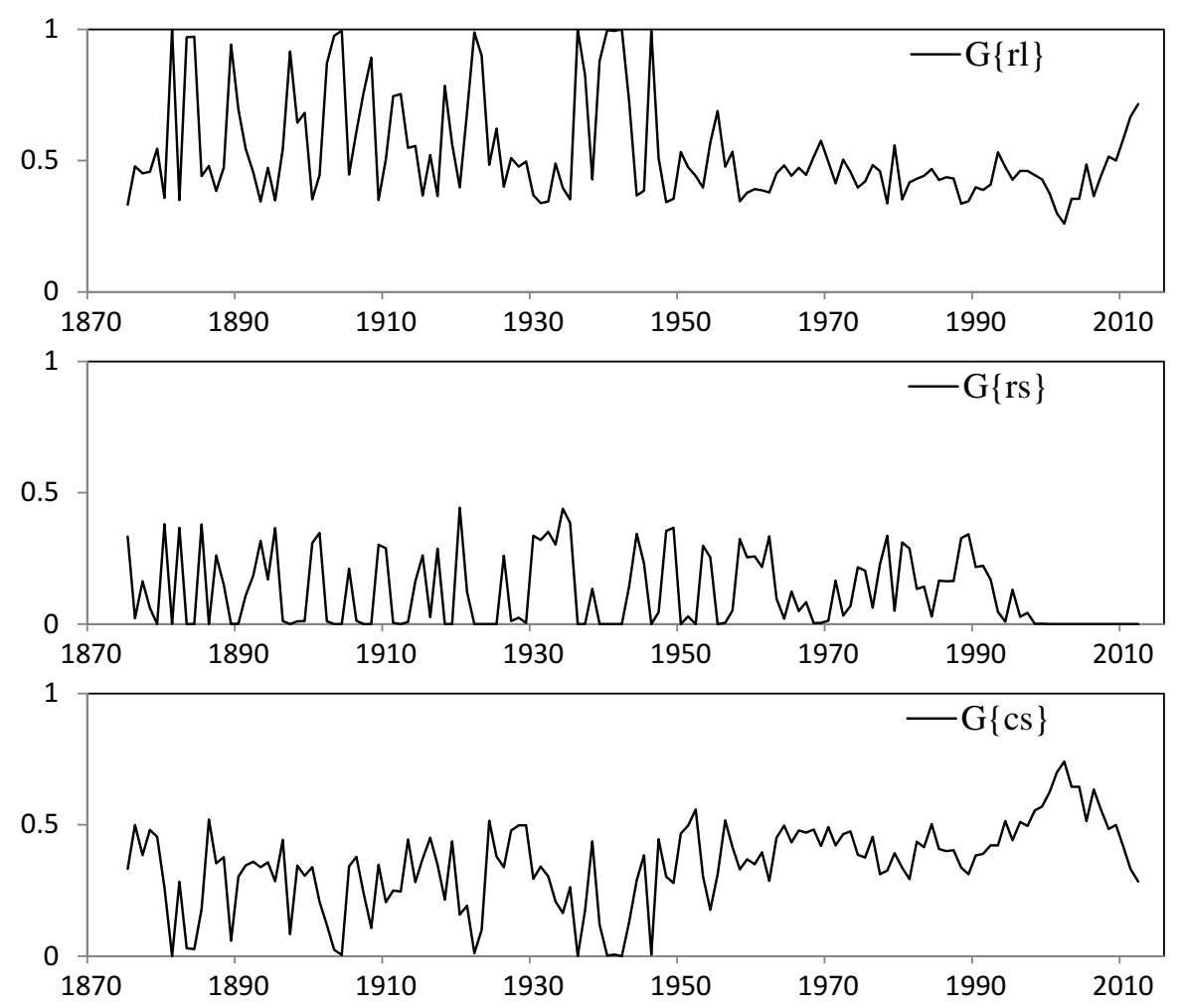

Figure 7: Time-varying fractions of long-term investors (top), rational short-term investors (middle) and contrarians (bottom)

finding of decreasing dividend yields reported by Fama and French (2001). The fraction of contrarians is relatively high during this period and increases further during the buildup of the 1990s bubble. The fraction of rational speculators stays rather low during the entire sample period.

Table 2 further shows estimates of the representative agent models considered in Section 3, with the difference that the parameter $\rho$ is now estimated using NLS. These models can be seen as a restricted version of the model (21)-(24). Instead of the evolutionary dynamics (22)-(23), the fractions $G_{t}^{r l}, G_{t}^{r s}$ and $G_{t}^{c s}$ are restricted to either zero or one. The parameters $\beta$ therefore drop from the model. The correlation coefficients, volatility ratios and $R^{2}$ reported in Table 2 suggest that the heterogeneous agent model is the preferred specification. The long-term model generates a higher correlation coefficient $\left(\operatorname{corr}\left(y_{t}^{r l}, y_{t}\right)>\operatorname{corr}\left(y_{t}^{h a}, y_{t}\right)\right)$ but in all other cases, the heterogeneous agent model generates higher correlation and volatility as well as a better fit in terms of $R^{2}$. The null hypothesis that $\phi=1$ is rejected for all three alternatives. 
The parameter $\rho$ is estimated under the restriction $0 \leq \rho \leq 1$. For the heterogeneous agent model, the estimate of $\rho$ is rather close to the calibration in Section 3. For the representative agent models, however, a corner solution is reached with $\rho$ estimated at either zero or one. In the log-linear approximation by Campbell and Shiller (1988), the parameter $\rho$ represents the mean of the ratio $\frac{P_{t}}{P_{t}+D_{t}}$. Of course, this mean can never be zero or one as this implies that either prices or dividends are always equal to zero. It is furthermore easy to see that the two speculative models (16) and (19) reduce to identical models in which one-period dividend expectations are the sole determinant of prices in the case that $\rho=0$. The finding that highly unrealistic values of $\rho$ are required to obtain the best fit can be interpreted as an economic rejection of the three representative agent models.

For a formal statistical comparison of the heterogeneous agent model and the three representative agent models I rely on the test for nonnested nonlinear regression models developed by Davidson and MacKinnon (1981). The test is based on the following regression:

$$
y_{t}=(1-\alpha) y_{t}^{H 1}+\alpha \widehat{y}_{t}^{H 2}+\eta_{t},
$$

in which $y_{t}^{H 1}$ and $y_{t}^{H 2}$ are two nonnested nonlinear regression models, such as the different models considered above. The parameters of $y_{t}^{H 1}$ are estimated jointly with $\alpha$ by NLS, while the test regression further includes the fitted values from NLS estimation of the model $y_{t}^{H 2}$. The hypothesis $H_{0}: \alpha=0$ is equivalent to the hypothesis that $y_{t}^{H 1}$ is the correct data generating process. Table 3 shows the estimates and standard errors of $\alpha$, from testing $y_{t}^{h a}$ against $y_{t}^{r l}, y_{t}^{r s}$ and $y_{t}^{c s}$ as well as vice-versa. The top row shows the result when $y_{t}^{H 1}=y_{t}^{h a}$. The hypothesis that $y_{t}^{h a}$ is correct, can not be rejected against any of the three alternatives. Moreover, the bottom row of Table 3 shows that the hypotheses that $y_{t}^{r l}, y_{t}^{r s}$ or $y_{t}^{c s}$ are correct are all rejected against the alternative $y_{t}^{H 2}=y_{t}^{h a}$. 
TABLE 3: Nonnested hypothesis tests

\begin{tabular}{cccc}
\hline & $r l$ & $r s$ & $c s$ \\
\hline H1: $h a$ & 0.792 & 0.611 & 0.611 \\
& $(0.662)$ & $(4.468)$ & $(4.342)$ \\
H2: $h a$ & 0.787 & 0.927 & 0.927 \\
& $(0.028)$ & $(0.024)$ & $(0.027)$ \\
\hline
\end{tabular}

Notes: NLS estimates of $\alpha$ in model (26). Top: $y_{t}^{H 1}=y_{t}^{h a}$ and $\widehat{y}_{t}^{H 2}=\widehat{y}_{t}^{j}, j \in\{r l, r s, c s\}$. Bottom: $y_{t}^{H 1}=y_{t}^{j}$, $j \in\{r l, r s, c s\}$ and $\hat{y}_{t}^{H 2}=\widehat{y}_{t}^{h a}$. Rejection of $H_{0}: \alpha=0$ implies rejection of $y_{t}^{H 1}$ (Davidson and MacKinnon, 1981). Annual data for 1872-2011. Standard errors (in parentheses) are computed using 10.000 bootstrap replications.

\section{Time-varying discount factors}

I have so far assumed a constant discount factor and, as a result, constant expected returns. The log-linear approximation by Campbell and Shiller (1988) does, however, allow for time-varying discount factors. If discount factors are allowed to vary over time, equation (7) becomes (disregarding the constant term $k$ ):

$$
y_{t}=\rho E_{t}\left[y_{t+1}\right]+E_{t}\left[\triangle d_{t+1}\right]-E_{t}\left[r_{t+1}\right] .
$$

There are several ways to model time-varying discount factors. Campbell and Shiller (1988) evaluate three simple specifications of the discount factors, based on short-term interest rates, consumption and volatility of the S\&P500 index, in addition to a constant discount factor. With a time-varying discount factor, expected returns are computed as follows:

$$
E_{t}\left[r_{t+1}\right]=\gamma E_{t}\left[x_{t+1}\right]
$$

in which $\gamma$ is the risk aversion coefficient and $x_{t}$ denotes interest rates, consumption or volatility. In the first case, $x_{t}$ is the log-yield on Treasury Bills (T-bills), representing the opportunity cost of capital. In the second case, $x_{t}$ is the log-growth rate of consumption, such that the model (27) becomes an consumption-based asset pricing model with constant relative-risk aversion utility function. In the third case, $x_{t}$ is the squared (lagged) 
log-return of the S\&P500 index, as a simple measure of market volatility or risk.

The constant-discount factor is nested in the time-varying specifications. When $\gamma=0$, it is easily seen that the expected return drops out from equation (27), reducing it to the constant discount factor models considered in the previous sections.

I evaluate the three specifications of the time-varying discount factor in the heterogeneous agent model (21). Following Campbell and Shiller (1988), I add $x_{t}$ as a third variable to the VAR model (12), after which the long-term model (15) with time-varying discount factor becomes:

$$
y_{t}^{r l}=\sum_{i=0}^{\infty} \rho^{i}\left(E_{t}\left[\triangle d_{t+1+i}\right]-E_{t}\left[r_{t+i+1}\right]\right)=\left(e_{2}^{\prime}-\gamma e_{3}^{\prime}\right) B(I-\rho B)^{-1} z_{t}
$$

while the speculative models (16) and (19) become:

$$
y_{t}^{r s}=\frac{\rho}{1-\rho} E_{t}\left[\triangle p_{t+1}\right]+E_{t}\left[\triangle d_{t+1}\right]-\frac{1}{1-\rho} E_{t}\left[r_{t+1}\right]
$$

and:

$$
y_{t}^{c s}=\frac{\rho}{1-\rho} \tilde{E}_{t}^{c s}\left[\triangle p_{t+1}\right]+E_{t}\left[\triangle d_{t+1}\right]-\frac{1}{1-\rho} E_{t}\left[r_{t+1}\right],
$$

in which:

$$
E_{t}\left[r_{t+1}\right]=\gamma e_{3}^{\prime} B z_{t}
$$

Due to limited data availability, the models with time-varying discount factors can be estimated only for the period 1891-2009. Campbell and Shiller (1988) find that these three time-varying discount factors are not helpful in explaining stock price movements in the long-run model. The results presented in Table 4 confirm that this finding also holds for the heterogeneous agent model considered here. Of the four specifications, the constant discount factor is the preferred option. Table 4 shows the correlation, volatility ratio and $R^{2}$ for the estimated heterogeneous agent models (21) with different time-varying discount factors as well as a constant discount factor over this period. The table further shows the NLS estimate of the risk aversion coefficient $\gamma$. Using the discount factor based on either 
TABLE 4: Time-varying discount factors

\begin{tabular}{lcccc}
\hline & $\gamma$ & $\sigma\left(y_{t}^{j}\right) / \sigma\left(y_{t}\right)$ & $\operatorname{corr}\left(y_{t}, y_{t}^{j}\right)$ & $R^{2}$ \\
\hline constant & $\cdot$ & 0.777 & 0.797 & 0.621 \\
\multirow{2}{*}{ T-Bill } & -0.013 & 0.690 & 0.687 & 0.467 \\
& $(0.304)$ & & & \\
consumption & 0.138 & 0.858 & 0.767 & 0.564 \\
& $(0.210)$ & & & \\
volatility & 0.824 & 0.714 & 0.794 & 0.618 \\
& $(0.157)$ & & & \\
\hline
\end{tabular}

Notes: NLS estimates and measures of fit for model (21)-(24), with constant discount factor or time-varying discount factor (28) based on interest rates, consumption or volatility. Annual data for 1891-2009. Standard errors (in in parentheses) are computed using 10.000 bootstrap replications.

interest rates or consumption, the restriction $\gamma=0$ (i.e. a constant discount factor) can not be rejected. These specifications are therefore not preferred to the constant discount factor model. Although the volatility ratio for the consumption based model is slightly higher than with the constant discount factor, the latter yields a higher correlation and a better fit overall.

In the case of a volatility-based discount factor, $\gamma$ is significant, but Table 4 shows that also this model is not an improvement in terms of correlation, volatility ratio or $R^{2}$ with respect to the constant discount factor model. Besides not improving the fit of the model nor increasing the volatility of replicated prices, including a time-varying discount factor based on volatility does not diminish the empirical need for heterogeneous horizons and expectations. As Figure 8 shows, with a volatility-based discount factor the estimated fractions of the different types evolve following a similar path as with a constant discount factor (Figure 7). In fact, the estimated fraction of contrarians is often even higher than with a constant discount factor.

Various more complex discount factor specifications, besides these three examples, could be considered. As Cochrane (2011) argues, for any behavioral model there exists an equivalent rational expectations model with time-varying discount factor. Nevertheless, this does not imply that modeling discount factors instead of expectations is always the most sensible strategy. The results presented in this paper show that a simple and straight- 

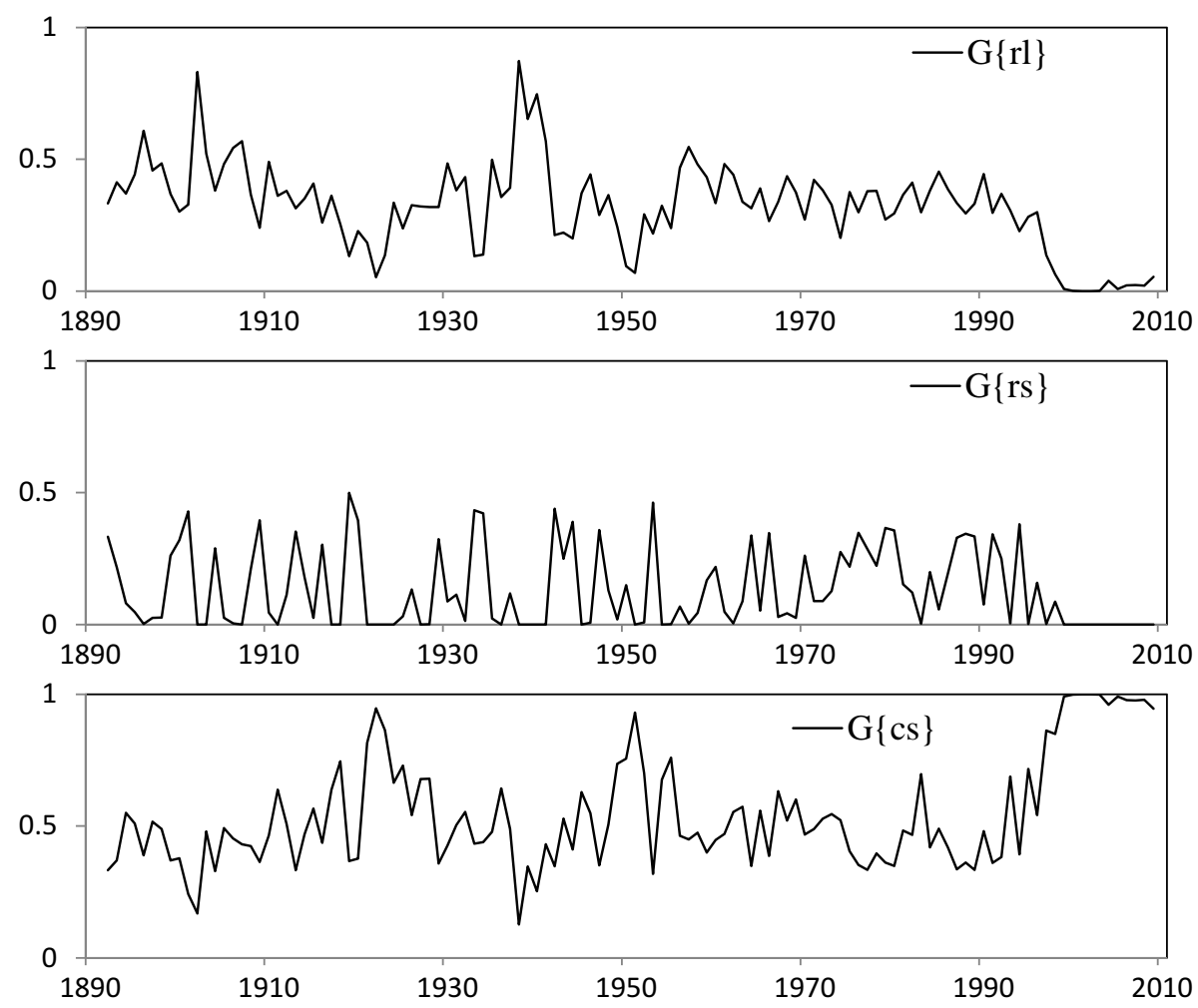

Figure 8: Time-varying fractions of long-term investors (top), rational short-term investors (middle) and contrarians (bottom), with volatility-based time-varying discount factor

forward extension (allowing for heterogeneous horizons and expectations) can generate significantly more volatility than the linear present value model. Specifying a parametric process for the evolution of a discount factor that is able to accomplishing the same result could instead be a rather complex task. The simple specifications considered in this section are at least not adequate.

\section{Conclusion}

I build a nonlinear asset pricing model in which all agents form expectations based on a VAR representation for price-dividend ratios and dividend growth rates. Based on the performance of each strategy in the previous period, agents choose between a long-term strategy, valuing asset based on expected dividends, and two types of short-term strategies, valuing assets mainly based on expected price changes. This heterogeneous agent model is able to generate far more volatile PD ratios than a standard present value model, thereby 
tackling a considerable part of the excess volatility puzzle.

The existence of speculators can explain the volatility of stock prices. Nevertheless, heterogeneity in expectations among the speculators is required in order to approximate observed prices in terms of volatility as well as correlation. In particular to replicate the stock market during the 1990s accurately, a large fraction of market participants needs to adopt contrarian beliefs. As this requires a deviation from the assumption of rationality, I argue that the 1990s bubble was not a rational bubble.

The introduction of time-varying discount factors into the model does not significantly alter the results. Overall, the results suggest that observed excess volatility with respect to the standard present value model is better explained by nonstandard expectations rather than by time-varying discount factors.

\section{References}

Ang, A. and G. Bekaert: 2002, 'International asset allocation with regime shifts'. Review of Financial studies 15(4), 1137-1187.

Anufriev, M. and G. Bottazzi: 2012, 'Asset Pricing with Heterogeneous Investment Horizons'. Studies in Nonlinear Dynamics \& Econometrics 16(4).

Barberis, N., A. Shleifer, and R. Vishny: 1998, 'A model of investor sentiment'. Journal of financial economics 49(3), 307-343.

Barberis, N. and R. Thaler: 2003, 'A survey of behavioral finance'. Handbook of the Economics of Finance 1, 1053-1128.

Blanchard, O. and M. Watson: 1982, 'Bubbles, Rational Expectations and Financial Markets'. NBER Working Paper (945).

Bloomfield, R. and J. Hales: 2002, 'Predicting the next step of a random walk: experimental evidence of regime-shifting beliefs'. Journal of Financial Economics 65(3), 397-414.

Bloomfield, R., M. O Hara, and G. Saar: 2009, 'How noise trading affects markets: An experimental analysis'. Review of Financial Studies 22(6), 2275-2302.

Boswijk, H. P., C. H. Hommes, and S. Manzan: 2007, 'Behavioral heterogeneity in stock prices'. Journal of Economic Dynamics and Control 31(6), 1938-1970.

Bradley, D., B. Jordan, and J. Ritter: 2008, 'Analyst behavior following IPOs: the 'bubble period' evidence'. Review of Financial Studies 21(1), 101-133. 
Branch, W. and G. Evans: 2010, 'Asset return dynamics and learning'. Review of Financial Studies 23(4), 1651-1680.

Branch, W. and G. Evans: 2011, 'Learning about risk and return: A simple model of bubbles and crashes'. American Economic Journal: Macroeconomics 3(3), 159-191.

Brock, W. A. and C. H. Hommes: 1997, 'A Rational Route to Randomness'. Econometrica 65(5), 1059-1096.

Brock, W. A. and C. H. Hommes: 1998, 'Heterogeneous beliefs and routes to chaos in a simple asset pricing model'. Journal of Economic Dynamics and Control 22(8-9), 1235-1274.

Campbell, J. and R. Shiller: 1987, 'Cointegration and Tests of Present Value Models'. Journal of Political Economy 95(5), 1062-1088.

Campbell, J. Y. and R. J. Shiller: 1988, 'The Dividend-Price Ratio and Expectations of Future Dividends and Discount Factors'. Review of Financial Studies 1(3), 195-228.

Cochrane, J. H.: 2011, 'Presidential Address: Discount Rates'. The Journal of Finance 66(4), $1047-1108$.

Cornea, A., C. Hommes, and D. Massaro: 2012, 'Behavioral Heterogeneity in US Inflation Dynamics'. CeNDEF Working paper.

Davidson, R. and J. MacKinnon: 1981, 'Several tests for model specification in the presence of alternative hypotheses'. Econometrica 49(3), 781-793.

De Long, J., A. Shleifer, L. Summers, and R. Waldmann: 1990a, 'Noise Trader Risk in Financial Markets'. Journal of Political Economy 98(4), 703-738.

De Long, J., A. Shleifer, L. Summers, and R. Waldmann: 1990b, 'Positive Feedback Investment Strategies and Destabilizing Rational Speculation'. The Journal of Finance pp. 379-395.

Dechow, P. and R. Sloan: 1997, 'Returns to contrarian investment strategies: Tests of naive expectations hypotheses'. Journal of Financial Economics 43(1), 3-27.

Engsted, T., T. Pedersen, and C. Tanggaard: 2012, 'The Log-Linear Return Approximation, Bubbles, and Predictability'. Journal of Financial and Quantitative Analysis 47(3), 643-665.

Fama, E. F. and K. R. French: 2001, 'Disappearing dividends: changing firm characteristics or lower propensity to pay?'. Journal of Financial Economics 60(1), 3-43.

Gilles, C. and S. LeRoy: 1991, 'Econometric aspects of the variance-bounds tests: A survey'. Review of Financial Studies 4(4), 753-791.

Grinblatt, M. and M. Keloharju: 2000, 'The investment behavior and performance of various investor types: a study of Finland's unique data set'. Journal of Financial Economics 55(1), 43-67.

Guidolin, M. and A. Timmermann: 2008, 'International asset allocation under regime switching, skew, and kurtosis preferences'. Review of Financial Studies 21(2), 889-935.

Gürkaynak, R.: 2008, 'Econometric Tests of Asset Price Bubbles: Taking Stock'. Journal of Economic Surveys 22(1), 166-186. 
Hirshleifer, D.: 2001, 'Investor psychology and asset pricing'. The Journal of Finance 56(4), $1533-1597$.

Hommes, C., J. Sonnemans, J. Tuinstra, and H. Van de Velden: 2005, 'Coordination of expectations in asset pricing experiments'. Review of Financial Studies 18(3), 955-980.

Hong, H. and J. Stein: 1999, 'A unified theory of underreaction, momentum trading, and overreaction in asset markets'. The Journal of Finance 54(6), 2143-2184.

Hong, H., J. Stein, and J. Yu: 2007, 'Simple forecasts and paradigm shifts'. The Journal of Finance 62(3), 1207-1242.

Jegadeesh, N. and S. Titman: 1995, 'Overreaction, delayed reaction, and contrarian profits'. Review of Financial Studies 8(4), 973-993.

Kaniel, R., G. Saar, and S. Titman: 2008, 'Individual investor trading and stock returns'. The Journal of Finance 63(1), 273-310.

Lakonishok, J., A. Shleifer, and R. Vishny: 1994, 'Contrarian Investment, Extrapolation, and Risk'. The Journal of Finance pp. 1541-1578.

Lof, M.: 2012a, 'Heterogeneity in stock prices: A STAR model with multivariate transition function'. Journal of Economic Dynamics and Control 36(12), 1845 - 1854.

Lof, M.: 2012b, 'Noncausality and Asset Pricing'. Studies in Nonlinear Dynamics and Econometrics (forthcoming).

Lütkepohl, H. and M. Krätzig: 2004, Applied time series econometrics. Cambridge University Press.

Ofek, E. and M. Richardson: 2003, 'DotCom Mania: The Rise and Fall of Internet Stock Prices'. The Journal of Finance 58(3), 1113-1138.

O'Hara, M.: 2008, 'Bubbles: Some perspectives (and loose talk) from history'. Review of Financial Studies 21(1), 11-17.

Park, A. and H. Sabourian: 2011, 'Herding and contrarian behavior in financial markets'. Econometrica 79(4), 973-1026.

Pástor, L. and P. Veronesi: 2006, 'Was there a Nasdaq bubble in the late 1990s?'. Journal of Financial Economics 81(1), 61-100.

Phillips, P., Y. Wu, and J. Yu: 2011, 'Explosive Behavior in the 1990s' NASDAQ: When Did Exuberance Escalate Asset Values?'. International economic review 52(1), 201-226.

Shiller, R.: 2003, 'From efficient markets theory to behavioral finance'. The Journal of Economic Perspectives 17(1), 83-104.

Shiller, R. J.: 1981, 'Do Stock Prices Move Too Much to be Justified by Subsequent Changes in Dividends?'. American Economic Review 71(3), 421-36.

Szafarz, A.: 2012, 'Financial crises in efficient markets: How fundamentalists fuel volatility'. Journal of Banking and Finance 36(1), 105 - 111. 
Timmerman, A.: 1994, 'Can agents learn to rational expectations? Some results on convergence and stability of learning in the UK stock market'. The Economic Journal pp. 777-797.

West, K. D.: 1988, 'Dividend Innovations and Stock Price Volatility'. Econometrica 56(1), 37-61. 